\title{
La lucha contra el Don Juan: La construcción de la masculinidad socialista ante la Segunda República a través de El Socialista (1930-1932)
}

\author{
The fight against Don Juan: The construction of \\ Socialist masculinity in the Second Spanish Republic \\ through «El Socialista» (1930-1932)
}

\author{
María Nieves García Pintor \\ Universidad de Granada, España \\ marinievesgp98@correo.ugr.es \\ https://orcid.org/0000-0002-3877-682X
}

Recibido: 25/09/2021

Aceptado: 08/11/2021

Cómo citar este artículo: GARCÍA PINTOR, María Nieves (2022). La lucha contra el Don Juan: la construcción de la masculinidad socialista ante la Segunda República a través de El Socialista (1930-1932). Pasado y Memoria. Revista de Historia Contemporánea, (24), pp. 165-188, https:// doi.org/10.14198/PASADO2022.24.07

\section{Resumen}

El objetivo principal del presente trabajo es poner de relevancia algunos de los ejes sobre los que giró el discurso de masculinidad emitido por el PSOE -a través de su principal órgano de difusión, El Socialista- durante los primeros años de la Segunda República Española. Se pretende conocer cómo en ese momento de reformulación política el pensamiento político, los ideales de género y la justificación del patriarcado convergieron en la creación de un determinado ideal masculino y femenino. Así, la difusión de un hombre entregado a la causa política, el desarrollo de una masculinidad comprometida con el hogar y la creación de otros a quienes contraponer ideales sociales y políticos fueron elementos clave a la hora de articular la identidad masculina socialista. 
Palabras clave: España; Nacionalismo; Masculinidad; Segunda República; Socialismo; Género; Discurso.

\begin{abstract}
The main objective of this paper is to highlight some of the axes on which the masculinity discourse -issued by the PSOE through its main publication, El Socialista- revolved during the first years of the Spanish Second Republic. The aim is to understand how, in a time of political reformulation, political thought, gender ideals, and the justification of patriarchy converged in the creation of a particular ideal for both men and women. Thus, the idea of a man devoted to the political cause, the development of a masculinity committed to the home, and the creation of «others» against whom to oppose social and political ideals were key elements in articulating the socialist masculine identity.
\end{abstract}

Keywords: Masculinity; Second Republic; Socialism; Gender; Nationalism; Spain; Discourse.

\title{
Introducción
}

«El obrero había de ser un buen esposo, un buen padre, amante de sus hijos, un leal compañero de oficio o profesión. Además, un buen ciudadano, que con su voto defendiese sus aspiraciones de clase.» ${ }^{1}$

Así plasmó el extremeño Juan Morán el ideal de obrero en 1930, con una definición que, atravesada por el género, la clase y la ciudadanía, sentó las bases del nuevo hombre que se intentó crear con la llegada del régimen republicano. Pero que, a su vez, pone de manifiesto el proceso de creación de toda una identidad masculina, obrera y socialista que se venía gestando desde finales del siglo XIX.

Cuando nos acercamos a la masculinidad obrera y socialista las cuestiones de género y clase convergen. La pronta vinculación del PSOE al republicanismo liberal y la situación económica y social de España a finales del siglo XIX y principios del siglo XX afectaron de manera determinante a su manera de configurar un ideal masculino y femenino (De Felipe Redondo, 2017: 65-85). Este proceso de definición de los géneros se agudizó con la posibilidad de la consecución del poder una vez instaurada la II República, provocando una modificación del discurso que adoptaría una proyección nacional. Estas afirmaciones nos llevan a entender la masculinidad socialista de finales de los años 20 y principios de los años 30 como una subcultura en auge, pues sus expectativas de convertirse en hegemónica, hasta cierto punto, eran reales. Teniendo en cuenta

1. Morán, Juan. El Sembrador, El Socialista, 9 de abril 1930, p. 4 
esto, el análisis parte del supuesto de que la llegada al poder de una coalición republicano-socialista, con una mayoría de votos obtenidos por los últimos, no solo implicó un cambio en la forma de entender la política por parte de quiénes emitieron los discursos, sino también un proceso de transición en la sociedad para que esta comprenda, sea partícipe y sienta como suyo el nuevo sistema político republicano. Este proceso necesitó de una proyección discursiva capaz de conectar las expectativas de vida de los obreros con el proyecto político y económico deseado por el PSOE, lo que llevó a la construcción de referentes identitarios plurales y, en ocasiones, a una resignificación de los referentes obreristas que afectaron a los ideales y expectativas de las clases populares.

A fin de penetrar en estos aspectos, el objetivo de este estudio es analizar el discurso que utilizó el PSOE para construir la masculinidad socialista entre 1930-1932 a través de uno de sus principales órganos de difusión, el periódico El Socialista. Se pretende también poner sobre la mesa los ejes sobre los que giró dicha configuración en oposición al ideal del Don Juan puesto que la elección de este ideal al que contraponerse no fue casual ya que se enmarca dentro de una corriente intelectual mucho más amplia que venía cuestionando las actitudes de este tipo de varones desde principio de siglo. Científicos como Gregorio Marañón calificaron al Don Juan como el símbolo de todos los actos inmorales que cometieron los hombres y que fueron señalados por las mujeres de la época; abandono del hogar, ausencia del cuidado de los hijos, alcoholismo, malos tratos, etc. pero también de la decadencia de España como nación, especialmente tras la pérdida colonial de 1898 (Aresti, 2001). Sin embargo, lo más relevante de esta crítica no fue tanto el juicio de valor sobre estas actitudes masculinas, sino que esta fue un punto de inflexión para la definición de lo que significaba ser un «hombre». Se abrió así un abanico de posibilidades para la creación de un nuevo proyecto masculino a nivel nacional. La medicina, el catolicismo o las derechas políticas lanzaron sus proyectos masculinos (Aresti, 2010), pero también las culturas políticas de izquierdas perfilaron las bases ideológicas, jerárquicas y de respetabilidad que debían de seguir los obreros. Son precisamente estas cuestiones las que se pretenden poner de relevancia en este artículo. Con esto no se afirma que estas premisas sean los únicas sobre las que el Socialismo construyó su ideal masculino, probablemente ni si quiera sean los principales, sino que lo que se pretende es esbozar las primeras líneas para un análisis de la masculinidad obrera en España. 
El marco ideológico: la introducción del cientifismo burgués y del discurso feminista en la formación del ideal masculino

A nivel práctico el discurso de género socialista se caracterizó por toda una serie de contradicciones marcadas por los virajes en las influencias de sus bases teóricas a finales del siglo XIX y principios del XX. Durante sus primeros años estuvo influenciado por numerosas corrientes ideológicas que acabarían por deformar al marxismo ortodoxo; el Krausismo, el Guesdismo francés, la Socialdemocracia alemana o un cientifismo de inspiración positivista y darwiniana fueron claves en la formación del pensamiento socialista (Fernández García, Peces-Barba Martínez, 1979: 358-367). Con el paso del tiempo estas influencias adoptaron nuevas formas de materialización política y ya en los años treinta encontramos un Socialismo caracterizado por su reformismo, republicanismo y por una gran influencia de científicos y burgueses. Estos intelectuales fueron los que introdujeron razonamientos científicos propios de la burguesía como la Teoría Higienista o la Teoría de la Diferenciación Sexual de Marañón, los cuales afectaron directamente a la configuración de los roles de género puesto que cambiarían la forma de entender a los sujetos (hombres y mujeres) y las relaciones que se daban entre ellos. Quizá el principal cambio y el más importante fue que se pasó de entender las relaciones entre géneros como un binomio inferioridad/superioridad a una comprensión de los géneros en base a la diferencia.

A priori este cientifismo liberal burgués podría haber generado cierta animadversión en los círculos socialistas ya que tropezaba con la realidad material de unos hogares obreros donde el trabajo femenino venía a suponer una parte importante del sustento económico familiar, pero lo cierto es que aparentemente no produjo ninguna contradicción en la forma de entender las relaciones entre géneros sino que al contrario, a ojos de la elite socialista, la ciencia en si misma se caracterizaba por ser un instrumento de conocimiento, por portar una fuerte crítica a la realidad de la época y por dar un impulso ético y moral a los individuos (Marín Campos, 1998: 36). Así, el discurso socialista comenzó a emplear términos similares a los del discurso burgués para definirse y representar a sus individuos ante esta, quedando impregnado de este carácter diferencial que, renegociado en base a unos valores y ética socialistas, produjeron una reformulación de las funciones sociales, valores, comportamientos, y atributos de ambos géneros. El mejor ejemplo de esta acogida del cientifismo burgués fue a aceptación que tuvieron los discursos de Marañón debido a la exaltación que hace del trabajo como forma digna de vida del hombre, así como por una concepción del amor distinta a épocas anteriores, aunque esta no implicaba que la mujer tuviera un mayor grado de 
independencia (Aresti, 2001: 124). Otros autores como Ortega y Gasset fueron claves en la construcción de ideales a los que contraponerse. El filósofo fue capaz de conectar con ciertos sectores del Socialismo debido a la crítica que hace del «señorito satisfecho». Este arquetipo masculino venía a representar a un hombre que, satisfecho con su ignorancia, se beneficiaba de las ventajas de las estructuras sociales creadas por la modernidad y creía que su destino está en lo que desea hacer y no en lo que tiene que ser (Herrera Guido 2005: 143144). Este pensamiento, como veremos más adelante, fue aceptado dentro del Socialismo identificando al señorito satisfecho con el burgués representándolo como un ente inmóvil, abusador y pasivo, frente al movimiento y vigorosidad constante que venían a representar la actividad laboral y política desarrollada por los obreros.

Por otro lado, hay que tener en cuenta que desde sus inicios el Socialismo planteó políticas de género en clave igualitarista tales como la eliminación de la explotación laboral de las mujeres y la desigualdad salarial frente a los varones, ahora bien, esto no implicaba que el Socialismo finisecular dejara de considerar a los obreros varones como los verdaderos protagonistas de la emancipación social y política del proletariado (Aguado, 2011: 146).

Según Mercedes Arbaiza (2000) a finales del siglo XIX se dio un doble proceso de reformulación de las actividades productivas y reproductivas femeninas; por un lado se produjo una revaloración social de las capacidades como madres de las mujeres, poniendo el acento en el potencial de transformación del orden social que podía ejercerse a través de su influencia en el hogar, por otro, se asiste a un cambio en la retórica sobre la domesticidad introduciéndose criterios de racionalidad económica al trabajo doméstico de las mujeres. Siguiendo esta lógica material se defendió la figura de la «ama de casa» como la mejor vía de optimización de la mano de obra femenina, creando un discurso que, bajo parámetros distintos al discurso burgués de domesticidad, no ofrecía en la práctica un final muy distinto para las mujeres obreras y para las burguesas.

No obstante con la llegada de las primeras décadas del siglo XX se produjo una división entre aquellos que naturalizaron la desigualdad de género con artículos como el de Luis Pereira quién en 1910 escribirá en El Socialista el artículo «¿Quién nos coserá los calcetines?» dónde ataca la formación intelectual de las mujeres para destacar el ideal femenino de domesticidad (Aguado, 2010: 135) y los diferentes grupos de mujeres que comienzan a formar las primeras agrupaciones femeninas socialistas. La Agrupación Femenina Socialista Madrileña (1910) o el Grupo Femenino Socialista de Bilbao (1904), fueron los primeros referentes para las mujeres socialistas. Sus objetivos eran variados e iban desde formar a defensoras del pensamiento socialista dentro del papel que 
la sociedad les otorgaba como madres y educadoras, hasta pretender subvertir las relaciones de género establecidas (Del Moral Vargas, 2005: 250). La presencia de estas propuestas alternativas de feminidad llevó a los círculos socialistas a entender de diferentes formas los roles de género. Al respecto Rosa María Capel (2008: 107) ha establecido tres formas distintas de entender la función social que las mujeres debían de cumplir durante el primer tercio del siglo XX. Una primera postura, encarnada por feministas como Amparo Martí, María de Lluria o María Cambrils que entendieron que el feminismo y Socialismo son movimientos diferentes pero conjugables en tanto que, en su fin, ambos buscan la emancipación de la mujer y paliar desigualdades específicas como las discriminaciones legales, sociales o familiares que sufrían las mujeres y los obreros. Pese a ello, el feminismo siempre quedaría supeditado a la consecución de la emancipación obrera.

En un segundo lugar, aquellos sectores que entienden la igualdad entre hombres y mujeres como un ideal político-jurídico más que social. Sus discursos giraron en torno a los preceptos patriarcales de la sociedad del momento, de manera que el verdadero valor de la mujer radicó en el amor al marido, a sus hijos y al hogar. Esto les llevó a tachar el feminismo de antinatural. Y finalmente, una tercera vía encarnada por aquellos/as que situaban al hombre como responsable de la emancipación de la mujer. Es decir, por un lado ha de tratar a la mujer como igual y por otro ha de inculcar los ideales socialistas a las mujeres de su alrededor a fin de que estas otorguen una educación socialista a sus hijos.

Todas estas visiones sobre el feminismo convergieron y condicionaron unos ideales que se encontraban en constante formación. Así, la cuestión de la masculinidad se vio influida por la pugna de estas diferentes visiones, e incluso por contradicciones discursivas entre las mismas, por ello no podemos perder esta visión totalizadora dentro de este análisis ya que no podemos hablar de un único «ideal socialista» sino, por el contrario, de una diversidad de ideales que van a converger pero que, en última instancia, van a tener la capacidad de representar a los participantes de la formación política.

\section{La masculinidad política socialista ante la Segunda República}

La coyuntura política de la Segunda República fue entendida como un momento de quiebra que sirvió para poner en marcha toda una serie de proyectos políticos que otorgaron una mayor libertad para la creación, modificación y representación de las identidades existentes. En este contexto, el Socialismo desarrolló todo un discurso de Nación donde convergieron sin problema los valores de defensa de los intereses proletarios y los nacionales (Forcadell, 2009: 
22). Este llegó a su máxima expresión con la conformación del gobierno junto a los republicanos, originando una relación de fidelidad hacia la República desde un punto de vista patriótico, pues a través de sus estructuras iniciarían el proceso hacia una sociedad sin clases (Valero y Martí Bataller, 2017: 301). Así, la representación de la nación y de la clase necesitó de un ideal masculino sobre el que proyectar sus expectativas sociales, políticas y nacionales, pero también a través del cual cambiar el habitus del Don Juan, aquel representante social de la «degeneración» que sufría España, otorgando valores renovados al significado de ser hombre.

Así, el discurso de masculinidad socialista hundió sus raíces en dos hechos económicos y sociales: la pobreza y los abusos del patrón. Estos habían servido para fundamentar también el clásico binomio social de burgueses y proletarios (Juliá, 1985: 45-46), por lo que no fueron una novedad a oídos de los obreros. Las huelgas violentas, el hambre y la explotación laboral sirvieron de imaginario sobre el que articular toda una serie de sentimientos (desazón, penuria, rabia, esperanza, etc.) que fueron usados como fuerza motora para reformular las actitudes varoniles. Esta fuerza se dirigió hacia diversas cuestiones, entre ellas el trabajo y el proyecto político. El trabajo fue el primer elemento de dignificación y unificación proletaria empleado por los socialistas desde inicios de siglo (Aresti, 2001: 232), pero en el contexto electoral en el que nos encontramos, el significado del trabajo adquirió una nueva dimensión puesto que no solo supuso el empleo de la propia fuerza de trabajo sino que este se basó en la capacidad de dispersar y luchar por la causa socialista:

«Todo esto (...) viene a indicar hasta donde nosotros, los socialistas, debemos llevar el sacrificio en pro de nuestra presente actuación y nuestra futura posición en la nueva España. Tenemos que exponer nuestras ideas sea como sea. (...) El camarada que esto lea estará acorde conmigo. Y se dispondrá al sacrificio. De cualquier forma. Porque es su deber. Más bien su obligación. O se es Hombre, o se es un ser humano nada más (...) Afortunadamente en el Partido Socialista abundan mucho los hombres. Es decir, abunda el espíritu de sacrificio» ${ }^{2}$.

El sacrificio para la consecución de la politización de las masas obreras constituyó uno de los pilares centrales en los sistemas de jerarquización y socialización masculinos dentro del partido. Esto llevó a la identificación de la existencia de dos tipos de hombres, los conocedores y los no conocedores de la doctrina marxista. Esta distinción fue clave en la elección de líderes, especialmente cuando se puso de manifiesto el principio de autoridad $^{3}$ que, aunque

2. Serrano Poncela, S. «Espíritu de Sacrificio», El Socialista 9 de abril de 1931, p.6.

3. Sin autor. «El principio de autoridad», El Socialista 8 de octubre de 1930, p.1. 
de raíces plenamente democráticas, otorgó a los conocedores de la doctrina un status superior a aquellos que, como afirmaba el sindicalista Lucio Martínez, «a falta de otros méritos, (tenían) la experiencia ${ }^{4}$. Este hecho no implicaba que no se reconociera la actividad política por parte de este tipo de hombres, sino que simplemente «Con Justicia y pudor todos pueden opinar sobre política» afirmaba Sócrates. Lo hemos repetido muchas veces: "opinar», no dirigir»"

La existencia de esta jerarquización pronto comenzó a generar problemas, ya que los obreros formados en la doctrina eran la minoría, planteándose opciones como la creación de escuelas de militantes ${ }^{6}$ para aprovisionar los puestos directivos de hombres conocedores de la doctrina y de la diversidad de problemas que se daban entre patronos y proletarios. Estos planteamientos no eran nuevos puesto que ya en 1912 se crearon de mano de las Juventudes Socialistas las «Escuelas Societarias» con la idea de formar a los militantes sindicales (Ramos, 2002: 55) o la Escuela Obrera de Madrid que en su momento más álgido (1932-1933) llegaría a contar con 250 participantes (Guereña y Tiana Ferrer, 2016). Pese a esto las iniciativas de los socialistas fueron limitadas en alcance generando todo un sistema de jerarquías que poco tuvieron que ver con la intelectualidad de los hombres. Se fomentó la creación de una masculinidad abnegada en favor de la causa política, especialmente en aquellos que solo tenían «la experiencia», mediante las acciones individuales o colectivas que se llevaban a cabo ${ }^{7}$. Así acciones que tuvieron que ver con la politización obrera como la dispersión de la propaganda se convirtieron en la forma fáctica de compromiso con el ideal, pero también en una forma de sociabilidad obrera y en una experiencia de camaradería entre varones, ya que esta acabó por articularse como una forma de reconocimiento del sacrificio realizado por los individuos en pro de la toma de conciencia del proletariado, especialmente en el contexto de cambio de régimen.

Junto a ello, y durante las elecciones de 1931, se desarrolló toda una campaña de vinculación del obrero a la patria, cuya misión fue la de dignificar a España mediante la consecución de la democracia y derechos para el pueblo ${ }^{8}$. Este patriotismo español pretendió impulsar un régimen representativo del interés nacional en el que las fuerzas obreras pudieran progresar (Martí Bataller,

4. Sin autor. «La acción socialista del obrero campesino,» El Socialista, 7 de enero de 1930, p. 4.

5. Esteban, María Encarnación. «Mientras la vida pasa», El Socialista, 21 de enero de 1932, p. 6.

6. Sin autor. «La formación de militantes», El Socialista, 18 de mayo de 1930, p. 3.

7. Salinas, Constantino. «Estamos satisfechos y orgullosos», El Socialista, 18 de febrero de 1930 , p. 1.

8. Sin autor. «Hoy, a votar», El socialista, 12 de abril de 1931, p.1. 
2017: 171). Para conseguir este objetivo se creó una vinculación entre la identidad de clase y la identidad nacional. Así, pronto la apatía por las cuestiones políticas provocó el arrebatamiento del sentido social de ser hombre pues no interesarse por la política indicaba «egoísmo mal entendido, pequeñez, aislamiento, insensibilidad de espiritu, indiferencia ante el bien y el mal; indica, efectivamente, no ser hombre» ${ }^{9}$. El hombre fue entendido como el ser político por naturaleza, y por ende la capacidad de protesta fue algo propiamente viril. Prueba de ello la tenemos cuando tiempo después en 1933 la Sociedad de Trabajadores de la Tierra de Guardamar del Segura se quejaba al Ministro de Trabajo usando las siguientes palabras «con todo respeto pero con energía y virilidad protestamos de las disposiciones dictadas por el ministro de trabajo ${ }^{10} \mathrm{O}$ cuando en 1932 las mujeres del barrio de Chamartín se lanzaron en protesta junto a sus compañeros tranviarios:

«Más dejemos a un lado todo lo ocurrido y fijémonos únicamente en el ejemplo viril, gallardo y noble de las mujeres, de esas mujeres proletarias que, identificadas con sus compañeros y con los huelguistas, se pusieron ayer junto a ellos para luchar por el triunfo. (...) Os manifestáis de forma magnifica por el pan de vuestros hijos y la razón de los tranviarios huelguistas ${ }^{11}$.

Fueron las cualidades que tradicionalmente habían definido al género masculino las que se depositaron en ellas cuando llevaron a cabo algún tipo de lucha política. Así, la mujer fue representada por la capacidad empática con el género masculino y con la búsqueda de un buen porvenir para sus hijos, y no como un ser político en sí mismo, considerando que aún debía de tomar conciencia sobre su situación y politizarse. La asunción de una naturaleza más sentimental que política en las mujeres llevó al desarrollo de todo un discurso donde valores ya mencionados como la empatía o el colaboracionismo intentaron arrebatar la conciencia femenina de su explotación en el trabajo y el hogar en pro del desarrollo de una conciencia política y de clase en clave masculina:

«[La mujer] comprendió en su trato constante con los trabajadores, en su contacto diario con la explotación de que se hace victima a su compañero, la necesidad de estar ella también en la organización para defender sus derechos de clase (...) Porque la mujer, aun dentro del hogar, realiza un trabajo ímprobo; más rudo que el de cualquier taller o fábrica; más agotador por no tener jornada fija. Y esta mujer, que en su casa realiza las funciones propias de su sexo tiene que acudir también a la organización. ¿Para arrancar reivindicación a su

9. Sin autor. «Hay que ser políticos», El Socialista 6 de septiembre de 1930, p.1.

10. Centro Documental de la Memoria Histórica, PS MADRID, 1627, 203.

11. Sin autor. «Mujeres proletarias», El Socialista 19 de enero de 1932, p. 5. 
esposo? No; sería absurdo. Pero puede y debe sindicarse para, en unión con las demás mujeres, luchar por el triunfo de una clase trabajadora» ${ }^{12}$

La necesidad de sindicación de las mujeres y, por otro lado, la existencia de una «agencia» femenina dentro del partido socialista fomentó el desarrollo de todo un discurso que aceptaba la participación femenina dentro de los órganos políticos pero sin implicar una verdadera alteración de los roles de género existentes. Ejemplo de ello fue la reivindicación que se hizo de la figura de «la mujer legisladora $»^{13}$, es decir, aquella mujer que a través de la participación política vela por su propia condición de esposa y de madre. De esta manera las convertían en un arma política y politizada pero sin abandonar su condición social impuesta. De hecho, autoras como Miren Llona (2014: 61-63) han demostrado como el ideal de madre consciente, propio de un conservadurismo ideológico, acabo penetrando en las clases populares donde la respetabilidad femenina giró en torno al cuidado de los hijos y del hogar.

Hay que tener en cuenta también que en muchas ocasiones estos discursos fueron contradictorios, ya que podemos ver como en un anuncio que se hace el 3 de enero de $1930^{14}$ se llama a la mujer obrera a la politización; «La mujer obrera debe de ser socialista por convencimiento, no por obediencia ciega a su compañero ¡Camaradas! ¡Llevad a vuestras mujeres e hijos a la Casa del Pueblo!». Pero estos discursos, aparentemente reconocedores de la autonomía femenina, no dejaban de entender que la politización de estas era una consecuencia de la responsabilidad masculina dentro del hogar como cabeza del mismo. Este ideal de domesticidad relegó a un según plano las particularidades del trabajo femenino y la labor que desarrollaban las mujeres dentro del hogar, priorizando una lucha de clases que debía de ser llevada a cabo por hombres y mujeres, pero que en última instancia favorecería indudablemente las condiciones de vida masculinas. De manera que no solo se colocó al hombre como el representante de la protesta proletaria, sino que lo alzaron como el responsable de la misma.

Los términos en los que se constituyó esta liberación fueron igualmente relevantes pues mientras que unos abogaban por la creación del «revolucionario silencioso» ${ }^{15}$, otros apostaban por unos términos mucho más violentos, influidos por la conflictividad política y social que impregnó este periodo y que llevó a la justificación del uso de la violencia política (González Calleja, Aróstegui Sánchez y Souto Krustin, 2000: 72). Así pues a partir de los últimos

12. Sin autor. «La mujer y la organización sindical», El Socialista, 24 de mayo de 1932, p. 4

13. De Lluria, María. «Pido la Palabra,»El socialista, 18 de marzo de 1930, p.4.

14. Sin autor. 3 de enero de 1930, p. 4.

15. Sin autor. «La revolución se aproxima. En las Cortes o en la calle», El Socialista, 9 de junio de 1931, p. 1. 
meses de 1931 se puso de relevancia un ideal que, basado en la difusión de unos nuevos parámetros de justicia patriótica, fue eminentemente violento ${ }^{16}$. Se dibujó la figura del «otro» políticamente hablando; burgueses, caciques y beatas, fueron entendidos como agentes anti-patrióticos, la anti-España que corrompía la Nación proletaria que los socialistas habían dibujado. Así,

«El mayor servicio que puede hacérsele a la República es el de impedir que se le acerquen gentes que no persiguen otro fin que el de profanarla, utilizándola en beneficio propio y en detrimento de la justicia $»^{17}$

Si el Socialismo concibió la llegada de la República como el reflejo de la conquista de la patria para la clase obrera, defenderla no solo implicaba apoyar la legalidad vigente sino también un acto de defensa de los intereses proletarios nacionales, y por tanto un paso importante en el acercamiento al ideal de una sociedad igualitaria. Así, el desafío a los que habían tenido el poder se consideró un acto de valentía y patriotismo, como es el caso de Francisco Hurtado cuyo enfrentamiento con los monárquicos en 1931 fue celebrado por El Socialista en estos términos:

«Está sano y salvo y además es un valiente. Porque la valentía no es el matonismo ni la temeridad. La valentía verdadera consiste en mantener un ideal y defenderlo, sea como sea, contra todo obstáculo. (...) Y el hecho tiene aún más mérito si se considera que los provocadores que le acorralaron venían en tropel y bien armados, en tanto que él estaba solo e indefenso. (...) Con hombres como este se puede contar para cualquier cosa grande» ${ }^{18}$

Esta resignificación de los valores violentos que encuadraban las actitudes masculinas dentro de la sociedad buscaba desarrollar un compromiso firme con la causa política y una actitud de militancia mucho más sólida. Así, la consecución del ideal político-social se entendió como un acercamiento a la propia virilidad en tanto que implicaba el compromiso del hombre con su conciencia de clase, su realidad social y la idea política que emanaba. El acto de Francisco Hurtado se vio especialmente reconocido, pero fue su individualidad en la defensa del ideal lo que le concedió el valor, al menos, de ser ejemplo para sus compañeros. Sin embargo la adopción de una masculinidad violenta no fue aceptada por todo el Socialismo, ya que hubo voces que se mantuvieron críticas ante este tipo de actitudes ${ }^{19}$ apostando por la creación de un obrero

16. Sin autor. «Una reacción expeditiva y saludable», El Socialista, 19 de abril de 1932, p.1. 17. Sin autor. "Caciquismo rural. El peligro Mayor», El Socialista, 6 de mayo de 1931, p. 4. 18. Sin autor. « ¡Bien por Hurtado! Eso es valor», El Socialista, 12 de mayo de 1931, p. 3. 19. Duenas, Seb. «Actos de Gobierno Socialista», El Socialista, 6 de abril de 1932, p.6. 
mucho más paciente, abnegado a la causa política y cuyos actos se mantuvieran dentro de la legalidad vigente ${ }^{20}$.

\section{¿Una masculinidad doméstica? Compromiso y paternidad en el socialismo}

La reformulación del ideal masculino no abarcó únicamente el ámbito de la militancia y participación en la política, sino que también implicó una modificación de las actitudes sociales que componían parte del ser socialista. La preocupación y el compromiso con el mundo que les rodeaba fueron claves en la articulación de unas relaciones sociales obreras donde el «espíritu de sacrificio» vino a simbolizar la esencia del hombre socialista. Así el modelo varonil comenzaba a perfilarse en medio de la necesidad práctica y de las teorías de los moralistas laicos, quiénes situaron al ideal del Don Juan como la raíz de los problemas sociales de la España del primer tercio del siglo XX (Aresti, 2012: 58-62). La alternativa que se propuso desde el Socialismo al arquetipo del Don Juan estuvo inspirada por su líder más carismático, Pablo Iglesias. Su figura fue moldeada por los distintos discursos atribuyendo a su personalidad distintas cualidades que fueron usadas como ejemplo a seguir, y es que, la figura de Iglesias resultaba convincente ya que no era un personaje imaginario o arquetipo, sino que era una hombre real cuya trayectoria vital enlazaba con los problemas de sus seguidores (Pérez Ledesma, 1993: 163). Tras su muerte en 1925 su figura se fue rodeando de un halo de misticismo que, elevado a lo etéreo, evocaba más a un ideal de un santo que el de que a un hombre del siglo XX. Su vida fue representada como una sacrificada y constante lucha por la manumisión de los demás ${ }^{21}$ y su labor de difusión del Socialismo fue definida como aquella del:

«Luchador obrero [que] no se desmaya, y con fuego de apóstol extiende su semilla y aumenta sus prosélitos (...) organiza a los adeptos y después comienza una descomunal batalla, como aquellas que nuestro señor Don Quijote para «desfacer entuertos y amparar desvalidos.» 22

El empleo de este lenguaje sacralizado para representar a un «santo laico» se debe a que no existían otros términos con suficiente reconocimiento social para describir gestas heroicas o comportamientos considerados ejemplares (Pérez Ledesma, 1987: 150), de manera que mediante este lenguaje conseguían

20. Sin autor. «En la plaza de toros de Jaén se celebra un imponente mitin», El Socialista, 12 de julio de 1932, p. 1.

21. Ramos Martínez, R. «Laboremos», El Socialista, 9 de diciembre de 1930, p. 2.

22. Escola, Francisco. «Pablo Iglesias, caballero andante del Ideal», El socialista, 12 de abril de 1930 , p. 6. 
magnificar los dichos y hechos del líder que servirían como ejemplo a seguir. También, podemos apreciar la tendencia existente durante estos primeros años de la República a recordar al Pablo Iglesias como líder revolucionario, lo que por otro lado encajó con la creación de todo un discurso histórico sobre el medievalismo español como un periodo de libertad y felicidad frente a la época de absolutismos perpetrados por reyes extranjeros durante la Edad Moderna, situación que solo podría ser revertida mediante la lucha por la consecución de la República (Marti Bataller, 2017: 87-91). Esta visión historicista del pasado provocó que se tomaran los viejos valores del caballero medieval, véase el ejemplo anterior de Don Quijote, como ejemplo de hombres con un férreo código moral, un comportamiento cortés con la mujer, y una lucha justa en el campo de batalla, elementos que encajarían con los ideales de rectitud de carácter, elevada moralidad, y buena instrucción que se venían difundiendo en los círculos socialistas desde antes de la muerte de Pablo Iglesias (Pérez Ledesma, 1993: 152). Así, el ideal de Caballero Medieval se consagraría con la difusión de lecturas como la del El Héroe, o El Discreto de Baltasar Gracián que fundamentaran histórica y socialmente la implantación de un ideal cercano al gentleman, aquel hombre de honor, recto en sus juicios y firme en sus decisiones ${ }^{23}$.

Estos viejos-nuevos modelos, se adaptaron y modificaron para encajar en las necesidades contemporáneas de lucha política y compromiso masculino. Y es que durante todo el periodo analizado El socialista se hizo eco de las diferentes problemáticas que azotaban los hogares proletarios, especialmente aquellas que tenían que ver con el maltrato hacia las mujeres, la prostitución, el abandono del hogar, el desamparo de los hijos o el alcoholismo. Todas estas actitudes atribuidas a los varones habían de cambiarse ya que la familia constituía la base primaria de la colectividad obrera internacional ${ }^{24}$ por lo que todo aquel que atentase contra su integridad o el bienestar de sus componentes lo hacía contra la unidad básica de unión del proletariado. Esto llevó aparejado la creación de una nueva concepción del ideal de hogar que traspasaba la esfera privada de convivencia familiar continua para abarcar un espacio de solidaridad obrera como fue la Casa del Pueblo. Fernando de los Ríos en la inauguración de la Casa del Pueblo de Calatayud lo definía así:

«Nuestro empeño significa que el Partido Socialista afirme su timbre de gloria, ennobleciendo al hombre; su máxima preocupación es el engrandecimiento interior de las casas humildes. (...) Se está elaborando en el mundo una moral

23. Sin autor. «Discursos de los camaradas Rodolfo Llopis y Fernando de los Ríos», El Socialista, 6 de mayo de 1932, p. 3.

24. Sin autor. «Socialismo y patriotismo», El Socialista, 6 de septiembre 1931, p.6. 
nueva de la solidaridad; entre los trabajadores ha brotado la mutualidad. Eso es lo que debe ser la Casa del Pueblo: una nueva escuela de mutualidad de los trabajadores. Esto lleva aparejados obligaciones y deberes. Ese es el nuevo ideal de hogar. Los hombres que no sepan seguir con sus compañeros una conducta igual a la que siguen en su hogar con su mujer, sus hijos y sus hermanos, esos nos estorban en nuestras filas» ${ }^{25}$.

De aquí emanan dos ideas claras, la primera es que el hogar (bien sea el público o el privado) necesita de unas obligaciones por parte de sus componentes y la segunda es que se intenta que se produzca una conexión entre la vida pública y la vida privada, de manera que los actos que llevara a cabo el hombre en su privacidad pudieran ser juzgados por la comunidad, quién otorgaría o no legitimidad social al individuo, lo que, a su vez, implicaba que la autoridad tradicional paterna dentro del hogar se viera cuestionada. Esto fue calificado por parte de los sectores eclesiásticos y derechistas como «la crisis de la familia» pero dentro del Socialismo no se entendió como tal pues esta suponía un acercamiento a ese ideal de supresión de la familia como una unidad económica individual dentro de la sociedad que estableció Engels (2017: 33) y por tanto un acercamiento a la virilidad ${ }^{26}$. Este cambio en el significado e importancia de la autoridad paterna dentro del hogar, nos habla ya de una tendencia al cambio del rol paterno dentro del hogar, alejándose del autoritarismo que había caracterizado a la figura paterna a finales del siglo XIX y principios del siglo XX (Crespo Sánchez y Hernández Franco, 2017: 218).

En estos momentos se intentó crear una imagen social de la paternidad mediante la muestra en público del cuidado de los hijos y de la familia; salir de paseo con la familia o coger a los hijos en brazos liberaban a la mujer de la carga del hogar ${ }^{27}$. Estas cuestiones implicaban una pérdida del orgullo varonil establecido, pero un acercamiento al ideal obrero y, sobretodo, un incentivo al hombre a participar del cuidado de los hijos/as. No obstante es significativo que no se hayan encontrado discursos que incentiven al cuidado dentro del hogar, por lo que se piensa que dicho cuidado sería más una forma de performar la paternidad en público como símbolo de responsabilidad dentro del mismo que unas verdadera implicación dentro de este. Así, la imagen del hombre como padre consciente tendría la capacidad de representar su compromiso con la familia y la mujer ante la comunidad, alejándose de la imagen que la burguesía

25. De los Rios, Fernando. «La inauguración de la Casa del Pueblo de Calatayud», El Socialista, 12 de abril de 1932, p. 1.

26. Sin autor. «La Crisis de la Familia y la Enfermedad de la Iglesia», El Socialista, 21 de mayo, 1930, p. 4.

27. Fabras Ribas, A. «Los Grandes Luchadores. Pablo Iglesias y su obra», El Socialista, 9 de diciembre de 1931, p. 4. 
había creado de los obreros como hombres dados al alcohol, la prostitución y el juego. A su vez esto provocó que la recuperación de su posición como cabeza de familia y por tanto se entendiese que sería a través de su mano por la que la mujer y los hijos se introducirían en el espacio público y se politizarían.

Todas estas cuestiones en la práctica plantearon varios problemas. El primero fue que situar al hombre como el cabeza de familia en el proceso politizador de esta implicaba una restricción en los espacios de clásicos sociabilidad masculinos (mítines, reuniones, tabernas, etc.) y segundo se produjo una desconexión entre lo que los dirigentes entendieron por «espacio de politización» y los espacios empleados por los obreros para esta. Quizá el caso más paradigmático fue el de la taberna. El alcoholismo de los obreros y las consecuencias que este traía al hogar llevaron al PSOE a emprender una lucha con este mal endémico de la clase obrera. Desde finales del siglo XIX se creó un binomio entre aquellos hombres conscientes de sus compromisos militantes y aquellos desmoralizados que con su alcoholismo ayudaban a mantener el sistema capitalista (Marín Campos, 1998: 33). Pero la persistencia de este discurso antialcohólico no indica más que los fracasos del mismo. Los obreros siguieron visitando la taberna, en buena medida porque era un espacio para la distracción y la discusión, ya que como afirma Eduardo «era la única diversión, se decía que el bar, la tasca, que era la universidad del obrero, era allí donde se juntaban los obreros y hablaban y discutían» (Hidalgo García-Orellán, 2013: 1326). Lo más probable es que la taberna se constituyera como uno de los ejes de politización de las clases obreras, pero las consecuencias que traía aparejadas como el alcoholismo o violencia, llevaron al discurso burgués a crear una imagen del obrero que el Socialismo pretendió subvertir con la difusión de esta idea de paternidad responsable pues vincularía de manera sentimental, política y económica al hombre con el hogar.

Esto implicó que se cuestionaran los espacios clásicos de sociabilidad masculina como fue la taberna pues la presencia de mujeres en esta no solo se consideró como un mal ejemplo para la moralidad de sus hijos (Campos Marín, 1990: 169), sino que el propio régimen de moralidad femenina se vería afectado por las formas propias de sociabilidad masculina que se daban en este tipo de espacios (Kaplan, 1995). Por tanto si el hombre arrastraba a su familia dentro de estos espacios considerados como «no respetables $»^{28}$ suponía su corrupción, y por ende, cualquier cabeza de familia que se preciara debía de frecuentar otros espacios que si fueron considerados respetables. Las alternativas fueron diversas, la Casa del Pueblo, las bibliotecas, el teatro, el cine o las galerías de

28. Ibídem

Pasado y Memoria. Revista de Historia Contemporánea, 24, 2022, pp. 165-188 
arte fueron anunciados constantemente en el periódico, pero estos, en el fondo, estaban más ligados con la aceptación de los parámetros de la cultura burguesa que la adopción de una cultura obrera propia o a una resignificación de los espacios de tradicionales de sociabilidad obrera.

Para finalizar, se ha de enmarcar el desarrollo de este discurso de "paternidad responsable» en un momento en el que el abandono del hogar y de la responsabilidad paterna llevaba implícito la conversión de la mujer en cabeza de familia, en tanto que era en el primer y único sustento económico de esta, perdiendo por tanto la consideración del trabajador como padre de familia que había desarrollado el movimiento obrero desde hacía casi un siglo (De Felipe Redondo, 2017: 74). Por ello, lo más probable es que a través de esta paternidad performativa se pretendiera restituir la figura del hombre como cabeza de familia, status que estaba perdiendo por las actitudes sociales del Don Juan.

Pese a estos intentos reformuladores lo cierto es que, en mayor o menor medida, las mujeres que se abrieron hueco en El Socialista adolecían del abandono del hogar por parte de los varones;

«El padre de su hijita disfruta de buena posición y podría sacar a su hija de la miseria: pensar que mientras él de nada carece la pobre niñita sufre los rigores del hambre. Es muy fácil ser tenorio en España. La ley ampara su libertinaje no obligándole a mantener a su hijo natural. $»^{29}$.

Las alusiones al Don Juan implicaron rápidamente la existencia de unas relaciones interclasistas entre burgueses y proletarias que fueron usadas por el Socialismo para realizar una crítica a su rival político, produciéndose una rápida identificación entre Burgués/Señorito y Don Juan que sirvió para definirse a ellos mismos en términos de lo que un obrero no debía de ser. Se adoptaron las premisas de autores como Ortega y Gasset que definieron al «señorito satisfecho» como aquel hombre que:

«Es el único ente de nuestra categoría zoológica que ni hace nada sino que toda su vida le es hecha. Incapaz de producir, todas las cosas del mundo, al llegar a él, se convierten en mejor dijes y ornamentos, que poner sobre su persona para vanidoso lucimiento.» ${ }^{30}$.

El señorito pues se situaba en las antípodas de lo que les hacía verdaderamente hombres a los obreros, que no era más que su dignidad de clase que emanaba de su trabajo ${ }^{31}$. Bajo la idea de la exaltación del trabajo físico, la fuerza, la rudeza y el dominio del mundo mecánico se forjó el «carácter» de

29. Una Socialista (seudónimo). «La mujer española,» El Socialista, 30 de julio de 1930, p.3 30. Sin autor. «Notas Breves», El Socialista, 27 de agosto de 1930, p. 1.

31. Regina. «Dignidad de Clase», El Socialista, 24 de diciembre de 1931, p. 3. 
los hombres socialistas, un carácter corpóreo abiertamente higienista con el que se intentó crear un cuerpo moralmente superior basado en la energía e inteligencia (Arbaiza, 2018: 90). En contraposición a esto se dibujó una clase burguesa inmovilista, carente de la energía que movía a los obreros en esa lucha que los incitaba a avanzar, en el sentido positivista del marxismo, hacia una sociedad igualitaria:

«Conocido es por todo el mundo el tipo del señorito. Llano, al nacer, el camino de su vida, sin un destello en su menguada mollera, asténica voluntad, exento de emociones altruistas, endereza su estéril vida al frívolo pasatiempo, no ve ni quiere ver las preocupaciones que en su torno voltean, no les interesa las quejumbres de sus semejantes ni las atribarlaciones de un pueblo vilmente sojuzgado, ni siente las inquietudes por aquistar la dignidad civil, los derechos inherentes a nuestra naturaleza. El señorito es una planta de estufa, sin aroma, sin promisión de fruto ${ }^{32}$.

Pero si por algo fue criticado socialmente el burgués fue por su habilidad de no empatizar con las condiciones es las que quedaban aquellas mujeres que, fruto del abandono del hogar del Don Juan, caían en la prostitución. Las abolicionistas socialistas no solo denunciaron actitudes de estos varones sino que también pusieron sobre la mesa que eran los burgueses, con los bajos salarios que pagaban a sus empleadas, los culpables de esta situación ${ }^{33}$. Así pues, la prostituta fue usada para evidenciar la doble moral burguesa, cuyo ideal varonil era el Don Juan, así como para remarcar la participación de la burguesía en la creación de un orden social abusivo con la clase obrera (Llona González, 2006, 738).

En este marco de modificación del hogar y de la familia también fue importante la reformulación de la unión matrimonial. Se expuso un rechazo a toda unión basada en algún interés, fomentándose el amor entre las parejas. De hecho, Ramón Pérez de Ayala se alegraba en 1931 de que en España no arraigara la costumbre de los «matrimonios de conveniencia» entre los socialistas $^{34}$. Pero este amor no estuvo exento de las infidelidades, de los «crímenes pasionales», de malos tratos, o en definitiva, la infelicidad de aquellos que componían la unidad familiar. El matrimonio se planteó como una «cadena

32. Sin autor. «Los despechados. Los señoritos revolucionarios», El Socialista, 29 de marzo de 1931, p. 1

33. García, Claudina «La crisis del trabajo y la prostitución», El Socialista, 21 de agosto de 1931 , p. 6.

34. Pérez de Ayala, Ramón. «Las mujeres harán la nueva España», El Socialista, 18 de julio de 1931, p. 6. 
irrompible dentro de la legalidad» ${ }^{35}$ por feministas como Hildegart Rodríguez y por tanto el divorcio fue la única solución posible a la realidad social de las mujeres. Sin duda esto implicaba una pérdida de autoridad del hombre sobre el la mujer que debía de justificar ante sus lectores, así se identificó al hombre con el «amo» y a la mujer con el «esclavo», tal como lo hizo Engels en su Origen de la Familia y la Propiedad Privada. De manera que el hombre habría de redimir a la mujer, pues solo así podría redimirse a sí mismo y acercarse a ese ideal igualitario de la sociedad.

No obstante el rol de la mujer dentro del matrimonio y el hogar adquirió nuevas formas de regulación que no alterarían sustancialmente los roles de género establecidos. La maternidad ocupó un lugar central en los deberes de la mujer dentro del hogar, se elevó como uno de los valores primordiales de la sociedad pues eran ellas las que otorgaban la vida y la educación a los hijos, y por ende las encargadas de educar a las futuras generaciones obreras (De Luis Martín, 2009: 289). Esta ideal de maternidad fue tal que, al hablar de la mujer beata se les fue arrebata su feminidad pues las «verdaderas mujeres» son las que «dan a luz y trabajaban y no quieren nada con los obispos ni las sacristías $»^{36} \mathrm{O}$ incluso se afirma que es «comprensible que la mujer que no ha podido cumplir los fines naturales de su sexo al llegar a cierta edad sea presa de segundo histerismo» ${ }^{37}$. De esta manera la maternidad se siguió entendiendo como la principal función social de la mujer, e incluso se instrumentalizó su capacidad reproductora en la lucha política pues sus entrañas llevaban la posibilidad del nacimiento de un obrero ${ }^{38}$. Esto implicaba el entendimiento del hogar y de sus labores como elementos propios de la mujer pese al discurso de una paternidad responsable. Ejemplo de esto es cómo a pesar de los postulados igualitaristas educativos que tuvo el Socialismo, en los informes escolares de la Fundación Cesáreo del Cerro se dejó claro los diferentes tipos de sociabilidad que ofrecían a niños y niñas:

«Las niñas aprendieron a coser laborcitas sencillas: vainicas, pespunte, punto de lado y cruceta. Los niños cultivaron su pedazo de campo, donde han visto nacer y llegar a fruto trigo, cebada, guisantes, judías, etc, etc» ${ }^{39}$.

35. Carrillo, Santiago «Una mujer moderna ante el problema eugénetico. Un libro de Hildegart», El Socialista, 3 de octubre de 1930, p.1

36. Sin autor. Las Damas Protestan, El Socialista, 27 de mayo de 1931, p.1

37. Nelken, Margarita «La Primavera la Sangre Altera», El Socialista, 21 de mayo de 1932, p. 1.

38. J.M. Carta abierta. Responderán las Mujeres, El Socialista, 3 de diciembre de 1931, p.1.

39. Sin autor. Fundación Cesáreo del Cerro. Gestión correspondiente al año 1931 que el Patronato presenta a la Asamblea de delegados de las Sociedades Obreras que conviven en la Casa del pueblo de Madrid, en la reunión que ha de celebrarse el día 28 de enero de 1932. El Socialista, 12 de enero de 1932, p. 3. 
Aunque las mujeres adquirieron el mismo conocimiento teórico que el hombre, la sociabilidad y deberes que la sociedad depositaba en ellas seguían girando en torno al ideal de domesticidad, incluso en los círculos obreros.

Esto complejizó el entendimiento de lo que debía de ser el trabajo femenino y las implicaciones que este podía causar dentro del hogar. Por ello el trabajo femenino y la lucha política masculina estuvieron íntimamente relacionados, de tal manera que el trabajo de las primeras nunca les fue negado pero sí que fue entendido con un carácter intermitente, al menos por una parte del Socialismo. Este solo debía de aparecer en determinados momentos, especialmente cuando el hombre estuviera luchado por la causa política ${ }^{40}$. De esta manera, se atendería a las demandas feministas sobre la necesidad de un trabajo femenino pero este únicamente aparecería cuando el hombre no pudiera ejercerlo. De hecho, en 1931 Benigno Cordeñoso animaba a las mujeres a asociarse de un modo particular:

«Hagamos de la mujer un aguerrido elemento de combate para la lucha por la transformación social anhelada, a fin de que en lugar de ser el enemigo casero el más formidable para la voluntad y la conciencia del hombre, reteniéndole en el hogar, siempre prediciendo catástrofes y ruinas cuando de nuestras luchas se trata, sea ella la primera en alentarnos con fortaleciendo nuestro espíritu y señalándonos el cumplimiento del deber, y si necesario fuera, dando ejemplo ocupando uno de los puntos en la vanguardia» ${ }^{41}$.

De esta forma se criticaron las actitudes de aquellas mujeres que requerían a su marido dentro del hogar, pues sus demandas hacían que el hombre no acudiera a la lucha proletaria o, al menos, no lo hiciera con tanto ímpetu. Esto dio un espacio muy concreto a la lucha femenina, entendiéndose como soporte y apoyo para un acto propiamente masculino. Ellas debían de ser el aliento de los hombres y motivarlos mientras que ellas participarían solo si fuese necesario. Sin embargo esta actitud escondía algo mucho más importante para la vida de las mujeres socialistas y es que la lucha por la consecución del ideal tuvo la capacidad de excusar al hombre del no cumplimiento de su deber dentro del hogar. En este sentido, cuando en 1932 Felipe Turuti en su artículo in memoriam de Giacomo Matteoti definió la relación familiar de este de la siguiente manera:

«Para sus hijos era como una tierna y amorosa madre: para su esposa, dulcemente entristecido por tener que dedicarse plenamente a la política que le absorbía su tiempo, tenía la sumisión sonriente de un hijo que reconoce

40. Castro, Victoria. «Para Unamuno. Envío», El socialista, 18 de junio de 1931, p. 2.

41. Cordeñoso, Benigno «La República y el feminismo», El Socialista, 21 de junio de 1931, p. 2. 
la justicia de los reproches y que ansía merecer siempre el cariño de la compañera ${ }^{42}$.

El incumplimiento de sus deberes como esposo se convertía en un mal menor ya que su lucha política estaba considerada como un elemento de categoría superior a su función de esposo y padre. Así, la ausencia paterna del hogar quedó justificada dentro pensamiento socialista, pero lo cierto es que no solventaba las demandas de las mujeres quiénes se siguieron viendo abocadas al cuidado y responsabilidad del hogar.

\section{Conclusiones}

El Socialista se consolidó como uno de los principales altavoces de la defensa obrerista ante la llegada de la Segunda República, y en sus páginas se plasmó la construcción de un discurso que osciló entre las necesidades políticas y la reformulación del ideal social para la implantación de un proyecto político que necesitaba de unas identidades que se vieran reflejadas en él. En el caso español encontramos como la experiencia política y la necesidad de politización de las masas va a ser uno de los elementos clave para modificar las actitudes sociales masculinas que se estaban dando encarnadas en el arquetipo del Don Juan. Para ello el sentido político de ser obrero se constituyó como uno de los pilares a los que se dirigió el discurso de masculinidad hegemónico, de manera que necesidad de desarrollar la conciencia de clase implicó que los valores de sacrificio y compromiso fuesen clave en el desarrollo de una masculinidad militante. No obstante, esta militancia acabó por articular sistemas jerárquicos dentro de las relaciones inter género basados en el conocimiento de la doctrina y la experiencia de vida que provocaron una fuerte división en el entendimiento entre quién podía liderar el partido y quién no podía hacerlo.

Esta capacidad política que fue otorgada a los hombres condujo a situarlos como ejes centrales de la lucha y por ende «brazo articulador» de la sociedad que le rodeaba, pues a través de ellos se debía de introducir a la familia y a la mujer en el ámbito público. Esto produjo una difusión entre la moral pública y privada que fue esencial para una reformulación de unas actitudes masculinas basada en la creación de un ideal de caballerosidad inspirado en la concepción de la Edad Media por parte del Socialismo y en la creación de una paternidad consciente del cuidado de los hijos. Mediante estas dos premisas se intenta solventar el problema del abandono paterno del hogar del que las mujeres obreras y feministas socialistas se quejaban, pero también fue a través de los cuales se

42. Turuti, Felipe. «El héroe», El Socialista, 12 de junio de 1932, p. 1. Traducción de un artículo publicado en revista italiana Critica Sociale. 
adaptaron nuevas formas de dominación masculina dentro del hogar. Frente al padre autoritario de finales del siglo XIX encontramos como en los años 30 se fomentó el cuidado de los hijos/as, aunque este se dirigió más hacia una forma de performar una responsabilidad que a un cambio en los roles de género. Se pretendía así devolver el lugar que estaba perdiendo dentro del hogar debido al mayor grado independencia económica y política que estaba adquiriendo la mujer. Así, se dieron nuevas atribuciones al ideal de domesticidad femenino, pese a las voces discordantes de María de Lejárraga, Manuel Cordero, Margarita Nelken, etc., donde la maternidad, la transmisión de valores, la empatía por su compañero y el apoyo en la lucha obrera se perfilaron como los deberes de una buena esposa y madre. Estos elementos no alterarían sustancialmente la posición de la mujer proletaria pero sí que justificarían a ojos de ambos sexos lo que era válido o no dentro de las relaciones matrimoniales e interpersonales proletarias.

Igual de importante fue el proceso de creación de los otros. Burgueses y beatas sirvieron a los socialistas para dibujarse en términos de lo que no son, afianzando no solo su pensamiento político y la lucha de clases, sino la creación de unas actitudes y valores sociales que diferenciaron a unos y a otros. Esta dialéctica entre el ideal burgués dominante y un discurso obrero reaccionario provocó en ocasiones la aceptación reformulada de parte de la cultura burguesa, pero a la vez una reiteración constante de las cualidades que colocaban al obrero en una escala moral diferente (y superior) a la del burgués para justificar sus deseos de hegemonía política y social.

En definitiva, el proceso de creación de una identidad obrera masculina abarcó distintos ámbitos, desde la politización de los obreros a la creación de unas normas sociales dentro de la comunidad y de la familia que van a ser claves en el inicio del proyecto social republicano y que sin duda tendrán una proyección en la Guerra Civil y el posterior Exilio.

\section{Bibliografía}

AGUADO, Ana (2003). Feminismo socialista y/o socialismo feminista: María Cambrils. Arenal. 10, 2. 243-254. file:///C:/Users/portatil/Downloads/16197Texto\%20del\%20art\%C3\%ADculo-46934-1-10-20201017.pdf

AGUADO, Ana (2010). Cultura socialista. Ciudadanía y feminismo en la España de los años veinte y treinta. Historia Social, n. ${ }^{\circ}$ 67.131-153.

AGUADO, Ana (2011). Politización femenina y pensamiento igualitario en la cultura socialista durante la Segunda República. En Ana AGUADO y Teresa ORTEGA (Eds.) Feminismos y antifeminismos: culturas políticas e identidades de género en la España del siglo XX (145-172). Valencia: Universidad de Valencia. 
ARBAIZA, Mercedes (2000). La cuestión social cómo cuestión de género. Feminidad y trabajo en España (1860-1930). Revista de Historia Contemporánea, 21, 395-458.

ARBAIZA, Mercedes (2018). «Sentir el cuerpo»: subjetividad y política en la sociedad de masas en España (1890-1093). Política y Sociedad, 55(1).71-92. https:// doi.org/10.5209/POSO.56798

ARESTI, Nerea (2001). Médicos, Don Juanes y Mujeres Modernas. Los ideales de feminidad y masculinidad en el primer tercio del siglo XX. Bilbao: Universidad del País Vasco.

ARESTI, Nerea (2005). Ideales y expectativas: la evolución de las relaciones de género en el primer tercio del siglo XX. Gerónimo de Uztariz, 21, 67-80.

ARESTI, Nerea (2010). Masculinidades en Tela de Juicio. Hombres y Género en el primer tercio del siglo XX. Valencia: Universidad de Valencia.

ARESTI, Nerea (2012). Masculinidad y nación en la España de los años 1920 y 1930. Mélanges de la Casa de Velázquez. Nouvelle série, (42-2), 55-72. https:// doi.org/10.4000/mcv. 4548

ARESTI, Nerea (2015). Cuestión de dignidad. Género, Feminismo y culturas políticas. En Carlos FORCADELL y Manuel SUAREZ CORTINA (coords). La restauración y la República 1874-1936. Vol. III (85-110). Madrid: Marcial Pons.

CAMPOS MARÍN, Ricardo (1998). El Obrero Abstemio. Salud, Moral y Política en el Discurso Antialcohólico Del Socialismo Español a Principios De Siglo. Historia Social, 31, 27-43.

CAMPOS MARÍN, Ricardo (1990). La instrumentalización de la mujer por la Medicina Social en España a principios de siglo: Su papel en la lucha antialcohólica. Asclepio, II. 161-173. https://doi.org/10.3989/asclepio.1990.v42.2.564

CAPEL MARTÍNEZ, Rosa María (2008). Mujer y socialismo (1848-1939). Pasado y Memoria. Revista de Historia Contemporánea, 7, 101-122. https://doi. org/10.14198/PASADO2008.7.06

CRESPO SÁNCHEZ, Francisco J. y HRNÁNDEZ FRANCO, Juan (2017). La construcción del modelo de paternidad en España (1870-1920). Relaciones Estudios de Historia y Sociedad, 150, 215-246. https://doi.org/10.24901/rehs. v38i150.302

DE FELIPE REDONDO, Jesús (2017). Masculinidad y movimiento obrero español: las identidades masculinas obreras y el trabajo femenino, 1830-1870. Historia, trabajo y sociedad, 8. 65-85.

DE LUIS MARTÍN, Francisco (2009). Familia, matrimonio y cuestión sexual en el socialismo español (1879-1926). En Francisco Javier LORENZO PINAR (ed.). La familia en la historia (261-291). Salamanca: Ediciones Universidad de Salamanca. 
DEL MORAL VARGAS, Marta (2005). El grupo femenino socialista de Madrid (1906-1914): Pioneras en la acción colectiva femenina. Cuadernos de Historia Contemporánea, 27, 247-268. https://doi.org/10.24901/rehs.v38i150.302

ENGELS, Friedrich (2017). El origen de la Familia, la Propiedad Privada y el Estado. Marxists Internet Archive. https://www.fundacionfedericoengels.net/images/ PDF/engels_origen_familia_interior_alta.pdf

FERNANDEZ GARCÍA, Eusebio y PECES-BARBA MARTÍNEZ, Gregorio (1979). Ideología Socialista 1879-1979. Madrid: Fundación Pablo Iglesias.

FORCADELL, Carlos (2009). Los socialistas y la nación. En Carlos FORCADELL, Ismael SAZ y Pilar SALOMÓN (Eds.) Discursos de España en el siglo XX (1534). Valencia: Universidad de Valencia.

GONZALEZ CALLEJA, Eduardo, ARÓSTEGUI SÁNCHEZ, Julio y SOUTO KRUSTIN, Sandra (2000). La violencia política en la España del siglo XX. Cuadernos de Historia Contemporánea, 22, 53-94.

GUEREÑA, Jean Louis y TIANA FERRER, Alejandro (2016). Influencias europeas en la educación popular española: El caso de la Casa del Pueblo de Madrid y el modelo belga (1897-1929). En Jean Louis GUEREÑA y Alejandro TIANA FERRER (Eds.) Formas y espacios de la educación popular en la Europa mediterránea. Siglos XIX y XX (167-185). Madrid: Casa de Velázquez. https://books. openedition.org/cvz/12967

HERRERA GUIDO, Rosario (2005). Ortega y Gasset: la rebelión de las masas cómo filosofía de la cultura. Devenires, 6(12), 134-152.

HIDALGO GARCÍA ORELLÁN, Sara (2013). Emociones en torno a la taberna en España: entre el asco y el orgullo de clase. Revista Electrónica Psicología Iztacala, no. 16(4), 1313-1338. https://www.iztacala.unam.mx/carreras/psicologia/psiclin/voll6num4/Vol16No4Art12.pdf

JULIÁ, Santos (1985). Un dualismo problemático. La herencia de Pablo Iglesias. Anthropos. Boletín de información y documentación, 45, 176-179.

KAPLAN, Michael (1995). New York City Tavern Violence and the Creation of a Working-Class Male Identity. Journal of the Early Republic, 15, 4, 591-617. https://doi.org/10.2307/3124015

KEEN, Maurice (2002). Origins of the English Gentleman: Heraldry, Chivalry and Gentility in Medieval England, c. 1300-1500. Stroud: Tempus.

LLONA GONZÁLEZ, Miren (2006). La Prostitución y la identidad de la clase obrera en el tránsito del siglo XIX al XX. Un análisis de género a la obra literaria de Julián Zugazagoitia. Revista de Historia Contemporánea, 33, 719-740.

LLONA GONZÁZLEZ, Miren (2014). Las contradicciones de la respetabilidad. Género y cultura política socialista en el primer tercio del siglo XX. Historia, Trabajo y Sociedad, 5, 45-64.

LORENTZEN, Jørgen (2013). The History of Fatherhood in Norway, 1850-2012. Nueva York: Palgrave Macmillan. https://doi.org/10.1057/9781137343383 
MARTÍ BATALLER, Aurelio (2017). España Socialista. El discurso nacional del PSOE durante la Segunda República. Madrid: CEPC.

PÉREZ LEDESMA, Manuel (1987). El obrero consciente. Madrid: Alianza Editorial. PÉREZ LEDESMA, Manuel (1993). La cultura socialista en los años veinte. En José Luis GARCÍA DELGADO, José ÁLVAREZ JUNCO, Paul AUBERT et al (Eds.) Los orígenes culturales de la II República (149-199). Madrid: Siglo XXI Editores. PRESTON, Paul (2020). La destrucción de la democracia en España. Reforma, Reacción y Revolución en la Segunda República. Barcelona: Debate.

RAMOS, María Dolores (2002). Modelos culturales, identidades y espacios intergeneracionales en el periodo 1917-1930. En María Dolores RAMOS y Ana AGUADO La modernización de España 1917-1939 (15-77). Madrid: Síntesis.

ROBLES EGEA, Antonio (2004). La Conjunción Republicano-Socialista: Una Síntesis De Liberalismo y Socialismo. Ayer, 54, 97-127.

SERRANO, Carlos (1989). Cultura Popular/Cultura Obrera en España alrededor De 1900. Historia Social, 4, 21-31.

STRANGE, Julie-Marie (20015). Fatherhood and the British Working Class, 18651914. Cambridge: Cambridge University Press.

VALERO GÓMEZ, Sergio y MARTÍ BATALLER, Aurelio (2017). «España es lo que nosotros pensamos»: División socialista e identidad nacional en el PSOE de la Segunda República. En Cristian FERRER GONZÁLEZ y Joel SANS MOLAS (Coords.) Fronteras Contemporáneas: identidades pueblos, mujeres y poder. Actas del V Encuentro de Jóvenes Investigadores en Historia Contemporánea. (291205). Barcelona: Universitat Autònoma de Barcelona, Departament d'Història Moderna i Contemporània y Asociación de Historia Contemporánea. 